\title{
CORROSION OF LOW-CARBON STEEL IN SODIUM CHLORIDE SOLUTION CONTAINING A WATER-SOLUBLE FRACTION OF HUMIC ACID
}

\author{
Leoš DOSKOČIL, Tomáš HORÁK, Jiří HONČ
}

Brno University of Technology, Faculty of Chemistry, Brno, Czech Republic, EU, doskocil@fch.vut.cz

https://doi.org/10.37904/metal.2021.4180

\begin{abstract}
Humic acids are a heterogeneous mixture of organic compounds that are naturally found in water and soil. In recent years, there has been a growing interest in the application of green fertilizers containing humic acids in agricultural activities. Water-soluble fraction of humic acid (WSHA) can be released from these fertilizers and subsequently interact with metallic materials (e.g. steel) located in soils and waters. WSHA were leached from an aqueous suspension of humic acids isolated from South Moravian lignite. Corrosion tests were performed on a low-carbon steel using a potentiodynamic polarization test and electrochemical impedance spectrometry. Results suggest that corrosion was initially promoted due to the formation of complex compounds of watersoluble humic acids with released iron ions. After a long time, a positive effect of WSHA was observed as the corrosion resistance of low-carbon steel increased.
\end{abstract}

Keywords: Corrosion, low-carbon steel, humic acid

\section{INTRODUCTION}

Low-carbon steel is a conventional engineering material widely used for a large range of applications including pipes for transport of gas or oil, sheet and strip products, plates, ship sides, wires and many others. The disadvantage of the steel materials is their susceptibility to corrosion, which can lead to dramatic degradation of mechanical properties [1].

Many of the low-carbon steel components are placed in the nature, where they can be subject to corrosion in water and soil. The failure of the components results in economic costs, and even more serious problem is, it can present particularly serious risks to human health and the environment [1,2]. It is well known that aggressive ions such as chlorides and sulfates present in water and soil cause corrosion of metallic materials. However, water and soil environments also contain various naturally occurring organic molecules, or natural organic matter, which can have a significant effect on the corrosion process due to their complex interactions on the metal surface and in the surrounding environment.

Natural organic matter represents the heterogeneous mixture of organic molecules and colloids in which humic substances (humic and fulvic acids) predominate [3]. Humic substances are traditionally divided based on their alkaline and acid solubility into three classes: humic acid, fulvic acid, and humin. Humic acids are characterized by high molecular weight and a high content of O-functional groups such as carboxylic and hydroxyl groups. Humic acid occurs not only in water and soil but also in peat, coal and leonardite, whereas their chemicalphysical properties may differ from each other depending on their origin. An increase in the content of humic acids (generally organic matter) in soil and water can be expected due to the growing interest in green agriculture and other interventions of human to the natural environment [4]. In connection with this fact, the interactions of organic substances with steel (generally metal materials) will become increasingly important. Therefore, the investigation of changes in the corrosion resistance/mechanisms of conventional materials such as low-carbon steel in the presence of humic acids may be a desirable challenge for corrosion science. 
To date, only a limited knowledge is provided about the effect of humic acids on low-carbon steel corrosion in both soil and water. As far as the authors are aware, there are several articles dealing with corrosion of metallic materials due to humic substances presence [5-8].

Based on the organic matter nature, different conclusions on the corrosion resistance/mechanism of lowcarbon steel in the literature are presented. Humic acid in sulfate solution were shown to promote the attack on sulfide-containing inclusions present in API 5LX65 steel [5]. As a result, pitting corrosion occurred. Other authors have reported that general corrosion occurred when carbon steel was exposed to fresh lake water with humic acid [6]. The presence of humic acid accelerated corrosion and led to the formation of weakly bound complexes with corrosion products. These organic molecules can also initiate barrier corrosion protection in the case of the galvanized steel surface [7]. Humic acid precipitation on the surface of galvanized steel, forming a thick layer of deposits acting as a physical barrier between the steel component and corrosive environment was observed in different study. The fraction rich in humic and fulvic acids, which was isolated from dissolved organic matter of municipal wastewater, reduced the corrosion rate of N80 carbon steel [9]. Unfortunately, the authors did not explain the observed improvement in corrosion resistance.

The aim of this work is to assess the effect of water-soluble fraction of humic acid (WSHA) on corrosion of lowcarbon steel in $\mathrm{NaCl}$ solution at room temperature. These organic molecules can be released by water from solid humic acid particles in nature and subsequently transported to the surface of metallic materials located in soil or water. The corrosion behavior of low-carbon steel was investigated by electrochemical tests involving potentiodynamic polarization (PDP) and electrochemical impedance spectrometry (EIS). Basic spectrometric characterization (UV-Vis and FTIR spectrometry) of the WSHA was also performed.

\section{MATERIAL AND METHODS}

The low carbon steel used in the experiments had the following the nominal composition, with mass ratios of $0.149 \% \mathrm{C}, 0.238 \% \mathrm{Si}, 0.368 \% \mathrm{Mn}, 0.011 \% \mathrm{P}$ and $0.0171 \% \mathrm{~S}$. The steel bar was cut into circular samples with a diameter of $1.5 \mathrm{~cm}$. These samples were ground using a series of waterproof abrasive papers of 800 , 1200,4000 grit, rinsed with water and isopropanol and dried by hot air.

An amount of two grams of humic acid was extracted in two liters of ultrapure water to obtain a water-soluble fraction of humic acid. The humic acid used was isolated from South Moravian lignite (mine in Mikulčice, Czech Republic) according to the procedure described in the literature [10]. After the extractions in water, the solids were separated by centrifugation and the supernatant was filtered through a filter $(0.45 \mu \mathrm{m})$. The filtrate containing the dissolved humic acid portion (or WSHA) was stored in a refrigerator, and then served as a stock solution for the preparation of corrosion test solutions.

WSHA was characterized by means of Ultraviolet-visible (UV-Vis) and Fourier-transform infrared (FTIR) spectrometries. UV-Vis spectrum was obtained on a Hitachi U-3900H UV/Vis spectrophotometer by recording the absorption spectrum between $200 \mathrm{~nm}$ and $900 \mathrm{~nm}$. Sample was measured in a $10 \mathrm{~mm}$ quartz cuvette and were blanked against water. FTIR spectrum was obtained in Attenuated Total Reflection (ATR) mode using a Nicolet iS50 spectrometer. Spectrum was recorded over the range $4000-400 \mathrm{~cm}^{-1}$ at $4 \mathrm{~cm}^{-1}$ resolutions and was the averages of 128 scans. The spectrum for air on a clean dry ATR diamond crystal was used as the background for the infrared measurements.

Electrochemical measurements were carried out using VSP-300 potentiostat. Conventional three electrodes glass cell was used with platinum counter electrode, saturated calomel electrode as reference electrode with Luggin capillary bridge and sample with geometric area $1 \mathrm{~cm}^{2}$ as working electrode. The potentiodynamic polarization curves were recorded in the range of $\pm 200 \mathrm{mV}$ vs. open circuit potential at a scanning rate of 1 $\mathrm{mV} / \mathrm{s}$. Before recording the polarization curves, the open circuit potential was stable within $2 \mathrm{~h}$. Measurements were performed in environment of $0.02 \mathrm{~mol} / \mathrm{L} \mathrm{NaCl}$ with WSHA $(0,1.1,2.1$ and $3.2 \mathrm{~g} / \mathrm{L})$ at room temperature. Electrochemical impedance spectroscopy (EIS) measurement was performed at range of $10 \mathrm{mHz}$ to $100 \mathrm{kHz}$ 
with $10 \mathrm{mV}$ perturbation signal. The EIS measurements were recorded at 1, 4, 8, 24, 96 and $168 \mathrm{~h}$ for 0.02 $\mathrm{mol} / \mathrm{L} \mathrm{NaCl}$ with and without $3.2 \mathrm{~g} / \mathrm{L}$ WSHA at room temperature.

\section{RESULTS AND DISCUSSION}

Extraction of lignite humic acid with ultrapure water yielded $3.2 \mathrm{mg}$ of WSHA per liter. This fraction was analyzed using UV-Vis and FTIR spectrometries.

The UV-Vis absorbance spectrum of WSHA is shown in (Figure 1). The spectrum with a wavelength greater than $220 \mathrm{~nm}$ is featureless and characterized by absence of maximum and/or minimum; absorbance decreases exponentially with increasing acquisition wavelength. The spectrum contains only a small recognizable peak at $203 \mathrm{~nm}$ which indicates benzenoid aromatic compound structures [11]. FTIR spectrum of WSHA, Figure 2, contains aliphatic groups $\left(2905\right.$ and $\left.2840 \mathrm{~cm}^{-1}\right)$, the presence of methyl and methylene groups are also confirmed by the band of $1457 \mathrm{~cm}^{-1}$. The bands at 1564 and $1369 \mathrm{~cm}^{-1}$ can be attributed to aromatic substances and methyl groups bound to aromatics, respectively. These bands can also be related to carboxylates. The presence of carboxyl groups is indicated by a band at $1700 \mathrm{~cm}^{-1}$. WSHA also contains aryl ether compounds $\left(1262 \mathrm{~cm}^{-1}\right)$, phenols and ethers $\left(1198\right.$ and $\left.1154 \mathrm{~cm}^{-1}\right)$, secondary and primary alcohols (1094 and $1037 \mathrm{~cm}^{-1}$ ). Out-of-plane C-H deformation bands were found in the $900-700 \mathrm{~cm}^{-1}$ region.

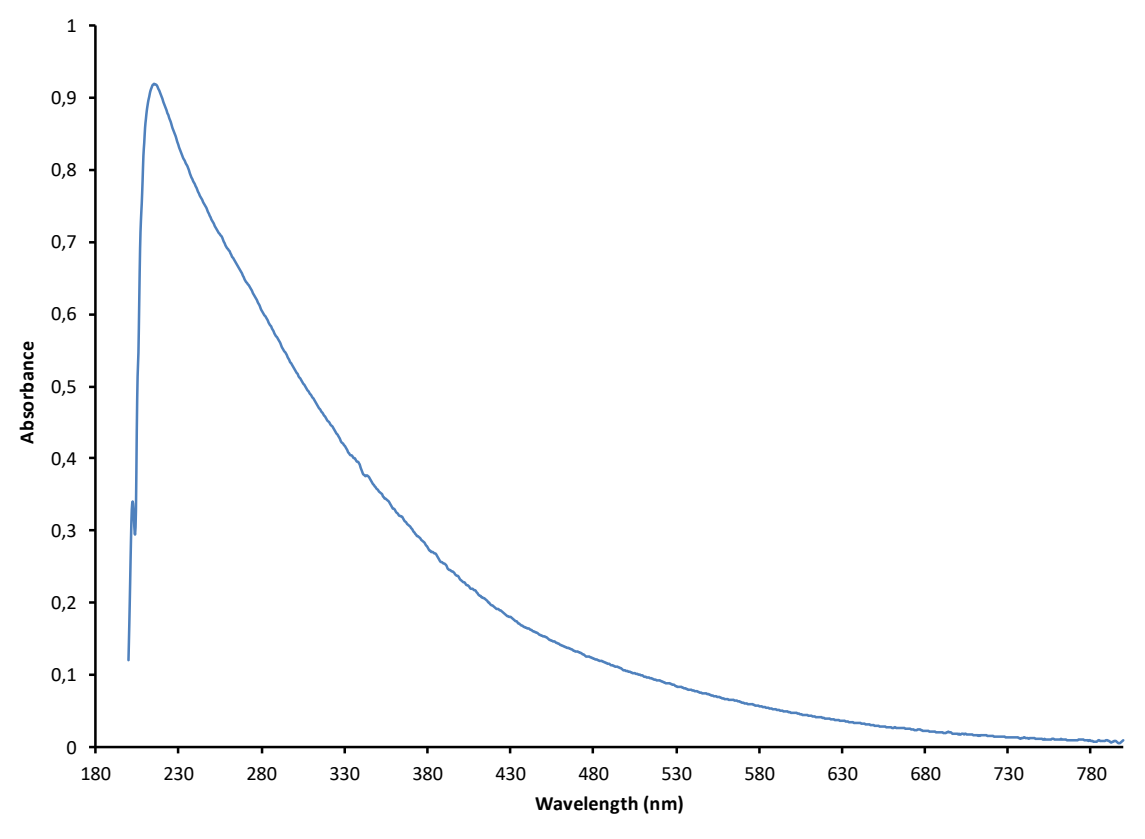

Figure 1 UV-Vis spectrum of WSHA.

Potentiodynamic curves, (Figure 3) show that increasing content of WSHA in a $0.02 \mathrm{~mol} / \mathrm{L} \mathrm{NaCl}$ environment led to a deterioration of the low-carbon steel corrosion. The $i_{\text {cor }}$ values, (Table 1), are consistent with this observation. The highest value of current density was found for corrosion medium containing $3.2 \mathrm{mg} / \mathrm{L} \mathrm{WSHA}$. The cathodic branch of the polarization curves indicates that the polarization is affected by the diffusion-limited current density. This observation is typical for corrosion of steels in $\mathrm{NaCl}$ solution. The negative impact of increasing concentrations of WSHA on the corrosion of low-carbon steel may be related to the complexation properties of the organic molecules. It is well known that humic acids form complex compounds with metal ions such as iron, zinc via carboxyl and hydroxyl groups [12]. These structural groups in WSHA were determined using UV-Vis and FTIR analysis in this work. A more detailed characterization of the fractions extracted from humic acids and South Moravian lignite has already been published in the literature [10]. 


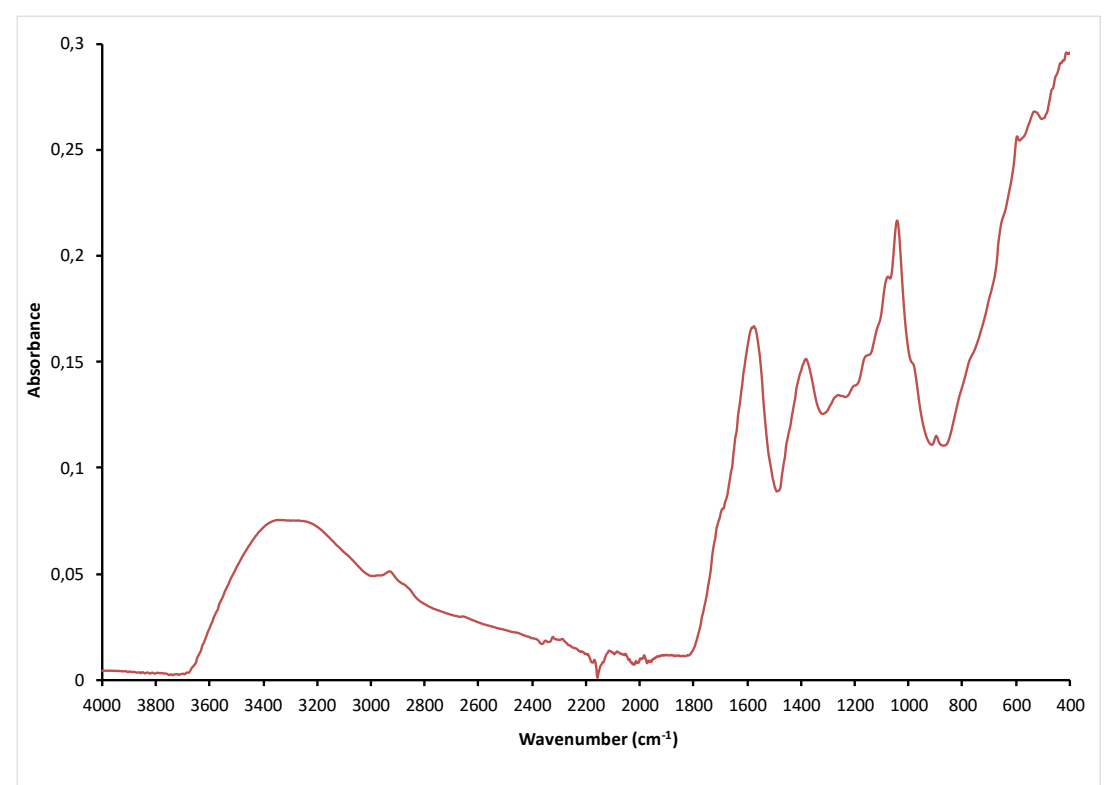

Figure 2 FTIR spectrum of WSHA.

Table 1 Parameters obtained from potentiodynamic polarization tests for WSHA in $0.02 \mathrm{~mol} / \mathrm{L} \mathrm{NaCl}$

\begin{tabular}{c|cccc}
\hline & $0.0 \mathrm{~g} / \mathrm{L}$ WSHA & $1.1 \mathrm{~g} / \mathrm{L}$ WSHA & $2.1 \mathrm{~g} / \mathrm{L}$ WSHA & $3.2 \mathrm{~g} / \mathrm{L}$ WSHA \\
\hline$E_{\text {cor }}(\mathrm{mV})$ & -557 & -564 & -567 & -572 \\
$\mathrm{i}_{\text {cor }}\left(\mu \mathrm{A} / \mathrm{cm}^{-2}\right)$ & 14.2 & 17.7 & 19.7 & 19.4 \\
\hline
\end{tabular}

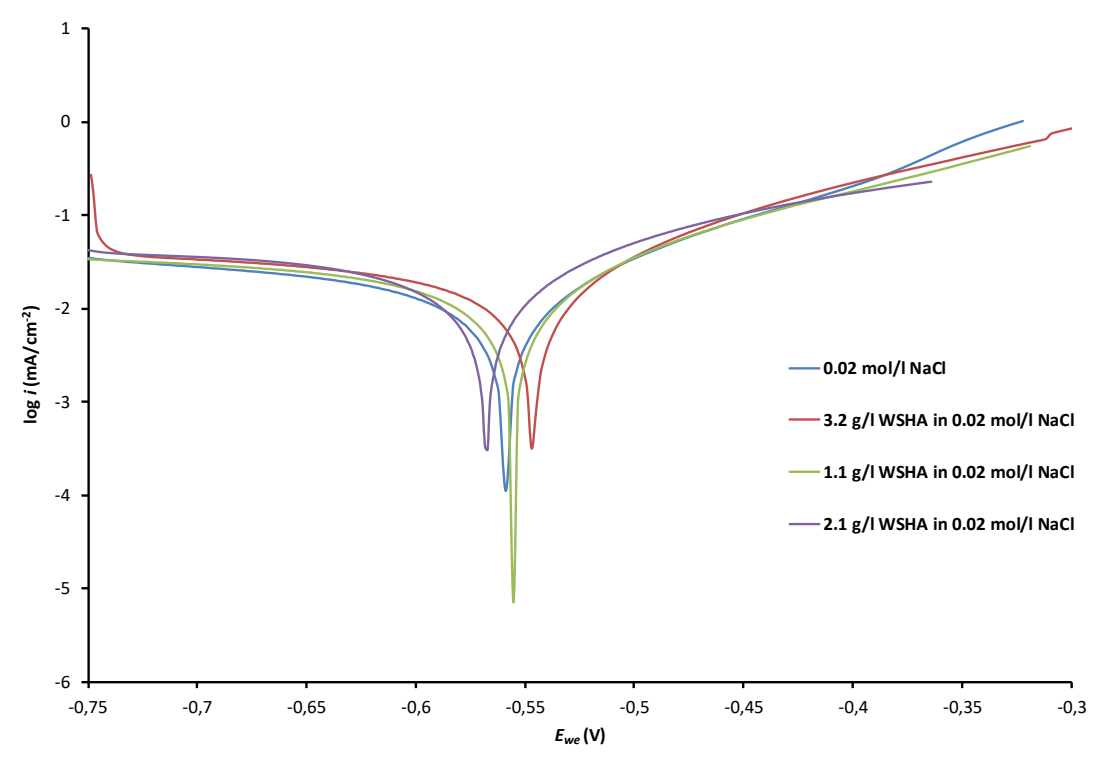

Figure 3 Potentiodynamic polarization curves.

EIS measurements were analyzed for $0.02 \mathrm{~mol} / \mathrm{L} \mathrm{NaCl}$ with and without $3.2 \mathrm{mg} / \mathrm{L}$ WSHA. The electrochemical equivalent circuit used for fitting impedance data consists of the solution resistance $\left(R_{s}\right)$ in series with the parallel combination of the constant phase element (CPE) and the charge-transfer resistance $\left(R_{t}\right)$. The constant phase elements are introduced in the model to describe the electrical property of double layer capacitors between electrode and electrolyte in order to take into account surface heterogeneity. 
The $R_{t}$ values indicate the degree of corrosion resistance; the lower the charge-transfer resistance, the higher the corrosion rate. For $0.02 \mathrm{~mol} / \mathrm{L} \mathrm{NaCl}$ solution with and without WSHA, the corrosion resistance $\left(\mathrm{R}_{\mathrm{t}}\right)$ increased continuously during the corrosion process.

The EIS measurements show that the corrosion resistance of the low-carbon steel was higher in the presence of the water-soluble fraction than in the $0.02 \mathrm{~mol} / \mathrm{L} \mathrm{NaCl}$ solution. This observation can be explained by the formation of an adsorption layer of WSHA on the surface of the corroding sample. The adsorbed organic molecules could act as a barrier to further dissolution of iron. The positive effect of water-soluble fraction was especially noticeable after a long time. As a result, it can be assumed that iron corrosion products are first formed, to which WSHA molecules are subsequently adsorbed.

The observations obtained from the EIS measurements and the potentiodynamic polarization tests seem to contradict each other. The results from the potentiodynamic polarization showed that the corrosion rate increases with the WSHA content. This is probably related to the fact that the potentiodynamic polarization is a rapid test and the physical barrier caused by adsorption of WSHA has not manifested itself. For this reason, the EIS method seems to be more suitable for studying the role of WSHA on the corrosion of low-carbon steel. The challenge for further research is whether the molecules preferentially bind to free iron ions in the solution or to corrosion products on the surface.

Table 2 Parameters obtained from EIS measurements.

\begin{tabular}{|c|c|c|c|c|c|c|c|c|}
\hline \multirow[b]{2}{*}{$t$ [hod] } & \multicolumn{4}{|c|}{$3.2 \mathrm{~g} / \mathrm{L}$ WSHA in $0.02 \mathrm{~mol} / \mathrm{L} \mathrm{NaCl}$} & \multicolumn{4}{|c|}{$0.02 \mathrm{~mol} / \mathrm{L} \mathrm{NaCl}$} \\
\hline & $R_{1}\left[\Omega \cdot \mathrm{cm}^{-2}\right]$ & $Q_{2}\left[\mathrm{M} \Omega \cdot \mathrm{cm}^{-2} \cdot \mathrm{s}^{\mathrm{a}}\right]$ & $a_{2}[-]$ & $R_{2}\left[\Omega \cdot \mathrm{cm}^{-2}\right]$ & $R_{1}\left[\Omega \cdot \mathrm{cm}^{-2}\right]$ & $Q_{2}\left[\mathrm{M} \Omega \cdot \mathrm{cm}^{-2} \cdot \mathrm{s}^{\mathrm{a}}\right]$ & $a_{2}[-]$ & $R_{2}\left[\Omega \cdot \mathrm{cm}^{-2}\right]$ \\
\hline 1 & 507 & 185 & 0,64 & 1650 & 589 & 773 & 0,79 & 1204 \\
\hline 4 & 491 & 125 & 0,77 & 3410 & 597 & 962 & 0,74 & 2137 \\
\hline 8 & 489 & 131 & 0,78 & 2050 & 599 & 1050 & 0,76 & 3463 \\
\hline 24 & 399 & 164 & 0,75 & 5310 & 590 & 954 & 0,79 & 4068 \\
\hline 96 & 284 & 167 & 0,81 & 8910 & 372 & 1576 & 0,83 & 5276 \\
\hline 168 & 365 & 323 & 0,77 & 9060 & 265 & 1957 & 0,78 & 5699 \\
\hline
\end{tabular}

\section{CONCLUSION}

The water-soluble fraction of lignite humic acid has a positive effect on the corrosion process of low-carbon steel in $\mathrm{NaCl}$. The beneficial effect can be observed after only one hour of exposure of the steel to the corrosive environment. Corrosion leads to the formation of corrosion products on the surface of steel, to which the molecules of the WSHA are subsequently adsorbed. As a result, the reduction in corrosion rate is particularly pronounced after prolonged exposure to the environment.

\section{ACKNOWLEDGEMENTS}

This work was supported by Specific University Research at FCH BUT, Project Nr. FCH-S-21-7553, Ministry of Education, Youth and Sports of the Czech Republic.

\section{REFERENCES}


[2] SHERIF, E.-S.M. A Comparative Study on the Electrochemical Corrosion Behavior of Iron and X-65 Steel in 4.0 wt \% Sodium Chloride Solution after Different Exposure Intervals. Molecules. 2014, vol. 19, no. 7, pp. 9962-9974.

[3] JUNG, A.-V., CHANUDET, V., GHANBAJA, J., LARTIGES, B.S., BERSILLON, J.-L. Coagulation of humic substances and dissolved organic matter with a ferric salt: An electron energy loss spectroscopy investigation. Water Research. 2005, vol. 39, pp. 3849-3862.

[4] DOSKOCIL, L., BURDIKOVÁ-SZEWIECZKOVA, J., ENEV. V., KALINA, L., WASSERBAUER, J. Spectral characterization and comparison of humic acids isolated from some European lignites. Fuel. 2018, vol. 213, pp. 123-132.

[5] DICK, L.F.P., RODRIGUES, L.M. Influence of Humic Substances on the Corrosion of the API 5LX65 Steel. Corrosion. 2006, vol. 62, no. 1, pp. 35-43.

[6] UMOREN, S.A., INAM, E.I., UDOIDIONG, A.A., OBOT, I.B., EDUOK U. M., KIM K.-W. Humic Acid from Livestock Dung: Ecofriendly Corrosion Inhibitor for 3SR Aluminum Alloy in Alkaline Medium. Chemical Engineering Communications. 2015, vol. 202, no. 2, pp. 206-216.

[7] JIANG, L., MAO, X., YU, J., GAN, F. Effect of humic acid on the corrosion behavior of carbon steel in natural freshwaters. Anti-Corrosion Methods and Materials. 2008, vol. 55, no. 4, pp. 204-207.

[8] SORIANO, C., Alfantazi A. Corrosion behavior of galvanized steel due to typical soil organics. Construction and Building Materials. 2016, vol. 102, pp. 904-912.

[9] SHEN, Z., ZHANG, S., DONG, X., SHI, J., FAN, J., LI, J. Inhibition effect of dissolved organic matter in secondary-treated municipal wastewater on corrosion of N80 carbon steel. Water Supply. 2019, vol. 19, no. 6, pp. 1653-1660.

[10] DOSKOCIL, L., GRASSET, L., ENEV, V., KALINA, L., PEKAR, M. Study of water-extractable fractions from South Moravian lignite. Environmental Earth Sciences. 2015, vol. 73, pp. 3873 - 3885.

[11] KORSHIN, G.V., LI, C.-W., BENJAMIN, M.M. Monitoring the properties of natural organic matter through UV spectroscopy: A consistent theory. Water Research. 1997, vol. 31, no. 7, pp. 1787-1795.

[12] ENEV, V., TURKEOVA, I., SZEWIECZKOVA, J., DOSKOCIL, L., KLUCAKOVA, M. Fluorescence analysis of $\mathrm{Cu}(\mathrm{II}), \mathrm{Pb}(\mathrm{II})$ and $\mathrm{Hg}$ (II) ion binding to humic and fulvic acids. Materials Science Forum. 2015, vol. 851, pp. 135140. 